\title{
Von Recklinghausen Disease with Palindiomic Rheumatism
}

JeR

\section{Tuba Tülay KOCA}

Physical Medicine and Rehabilitation Clinic, Malatya State Hospital, Malatya, Turkey.

Abstract:

Introduction: Neurofibromatosis (NF) is an autosomal dominantly inherited disease, classified as NF type 1 (von Recklinghausen disease) and type 2 (NF2). Palindromic rheumatism can be characterized either by permanent deformity or rapid arthritic or para-arthritic attacks that do not cause radiographic changes. These attacks can continue for hours, days, or weeks. Case Report: A 59-year-old female presented with diffuse pain and joint swelling attacks that had prevailed for one year. Many soft neurofibromas were observed on her body, with skin-colored palpations ranging in size from 0.5 to $5 \mathrm{~cm}$. Brown, mm-sized, axillary freckles were observed on both her underarms. There were five cafe-au-lait spots on abdominal trunk. Diffuse sensitivity and swelling was observed on both wrists. She had thoracolumbar kyphoscoliosis and macrocephaly. Conclusion: Palindromic rheumatism in a NF has rarely been reported.

Key words: Arthritis, Neurofibroma, Neurofibromatoses, Pain, Palindromic Rheumatism.

\section{Introduction}

Type $1 \mathrm{NF}$ is a common autosomal-dominant genetic disease, affecting 1 in 3,000 live births, with high penetrance and a variable clinical picture [1]. Classic features of type 1 NF consist of cutaneous (café-au-lait spots, skin neurofibroma), ophthalmic (pigmented iris hamartomas), and neurologic (tumors of the central and peripheral nervous system) manifestations. Musculoskeletal involvement is common in type $1 \mathrm{NF}(20-50 \%)$ [2].

Palindromic rheumatism can be characterized either by permanent deformity or rapid arthritic or para-arthritic attacks that do not cause radiographic changes. These attacks can continue for hours, days, or few weeks [3]. Patients in remission do not have any symptoms, and acute-phase reactant levels are normal. The most commonly affected joints are finger joints, wrists, and knees; however, other joints often are involved. Despite the occurrence of frequent attacks, the arthritis of palindromic rheumatism characteristically is non-deforming [4]. Here, we present a 59-year-old female with NF1 who visited our clinic with diffuse pain and joint swelling attacks and diagnosed as palindromic rheumatism.

\section{Case Report}

A 59-year-old female visited our clinic with diffuse pain and joint swelling attacks (duration of five days) on both of her hands that had prevailed for

\section{Corresponding Author: Dr. Tuba Tülay KOCA}

Email: tuba_baglan@yahoo.com

Received: July 14, 2016 | Accepted: October 11, 2016 | Published Online: October 14, 2016

This is an Open Access article distributed under the terms of the Creative Commons Attribution License (creativecommons.org/licenses/by/3.0)

Conflict of interest: None declared | Source of funding: Nil | DOl: http://dx.doi.org/10.17659/01.2016.0136 
one year. From her medical history, we learned that she has twice had anal apse surgery. Many soft neurofibromas were observed on her body, with skin-colored palpations ranging in size from 0.5 to $5 \mathrm{~cm}$ [Fig. 1]. There were five café-au-lait spots on the front and back of her body [Fig.1]. Brown, mmsized, axillary freckles were observed on both her underarms [Fig.2]. Diffuse sensitivity and swelling was observed in both her proximal and interphalangeal hand joints and wrists asymmetrically. She had thoracolumbar kyphoscoliosis and macrocephaly [Fig.3].

The following results are from her laboratory test: sedimentation rate: $76 \mathrm{~mm} /$ hour; C-reactive protein: $4.33 \mathrm{mg} / \mathrm{dL}$ (0-0.5); rheumatoid factor: $0.3 \mathrm{IU} / \mathrm{mL}$ (0-30). Anti-citrullinated peptide and antikeratin antibodies were not done. Her parathyroid hormone level, thyroid function tests, vitamin $D$, calcium, and alkaline phosphatase values were within normal limits. In her bone densitometry test her spinal L 1-4, t-score was -2.9 and the $z$-score was -1.2. She was diagnosed with palindromic rheumatism and osteoporosis; we prescribed methotrexate $6 \times 5 \mathrm{mg} / \mathrm{per}$ week, colchicine $3 \times 0.6 \mathrm{mg} /$ day, hydroxychloroquine $2 \times 200 \mathrm{mg} /$ day, methyl prednisolone I x4 mg/day, $1200 \mathrm{mg}$ calcium plus $800 \mathrm{IU}$ vitamin $\mathrm{D} /$ day and zoledronic acid $1 \times 5 \mathrm{mg} / 100 \mathrm{~mL} /$ year by intravenous infusion. Brain resonance imaging revealed ischemic gliotic focuses and neurofibromas; abdominal ultrasonography showed splenomegaly; in a thyroid ultrasound 6-mm hypoechoic nodule was detected in her right lobe. Erosion was not observed in either of her wrists or hand joints. In spinal conventional radiography, her vertebrae were osteoporotic; a left-sided kyphoscoliosis was observed. The patient's joint complaints and acute phase reactants regressed in her subsequent check-ups.

\section{Discussion}

NF1 causes abnormalities involving the musculoskeletal system, ocular disorders, skin

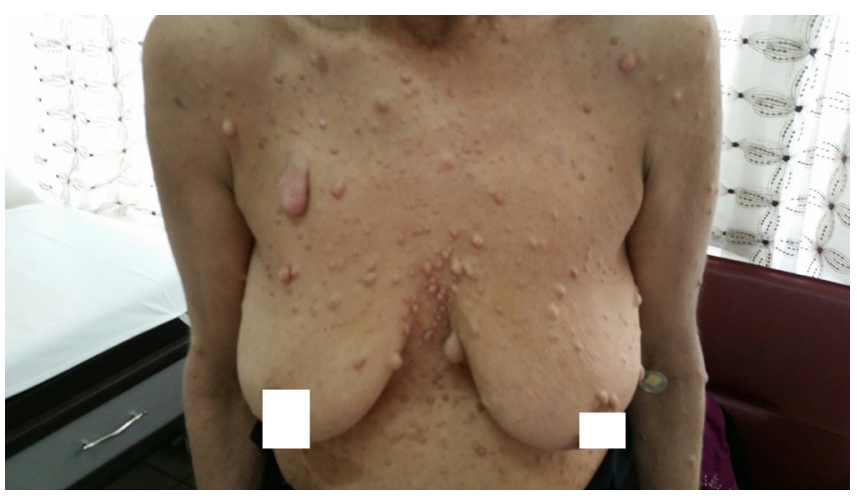

Fig. 1: Neurofibromas observed on the patient's body, with skin-colored palpations ranging in size from $0.5 \mathrm{~cm}$ to $5 \mathrm{~cm}$.

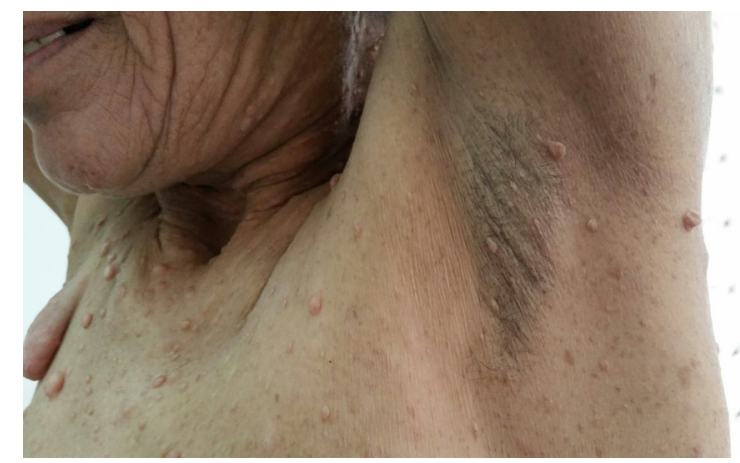

Fig.2: Brown axillary freckles were observed on both her underarms.

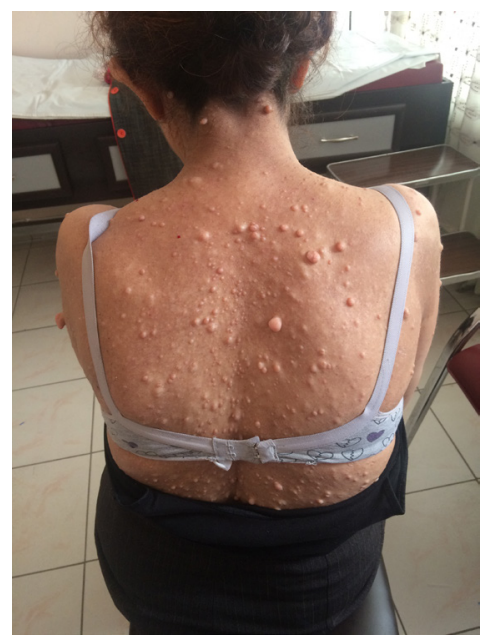

Fig.3: Thoracolumbar kyphoscoliosis. 
lesions (neurofibromas, "café-au-lait"spots), and neurologic system disorders (spinal neurofibroma, macrocephaly, tics, epilepsy). Musculoskeletal abnormalities include short stature, scoliosis, spinal deformities, congenital pseudoarthrosis, and bone dysplasia of the tibia $[5,6]$. NF1 also causes severe osteoporosis and leads to bone pain and pathological fractures [7].

She has been complaining of joint swelling on her hand joints asymmetrically lasting for five days. At the end of the $5^{\text {th }}$ day she had no symptoms or signs. But for the last months her attacks were seen more frequently. No joint deformity was present on physical and radiographic examination. In differential diagnosis palindromic rheumatism, viral arthritis, spondyloarthritis related seronegative arthritis, perniosis, early onset rheumatoid arthritis, para-neoplastic arthritis may be listed.

Palindromic rheumatism can be characterized either by permanent deformity or rapid arthritic or para-arthritic attacks that do not cause radiographic changes. These attacks can continue for hours, days, or 1 to 2 weeks $[8,9]$. Rheumatic factor (RF) or anti-citrullinated peptide is positive in $50 \%-70 \%$ of these patients; it is most likely that they will develop rheumatoid arthritis. In seronegative patients, palindromic rheumatism can be part of auto-inflammatory disease because of a high frequency of MEFV mutation [8]. Hydroxychloroquine can delay progression to rheumatoid arthritis or to other connective tissue disease [9].

To best of our knowledge, the association between palindromic rheumatism and NF1 has never been described before in the literature. Although it is rare, NFl can be associated in sporadic or exceptional way with palindromic rheumatism. A physiopathological link between the both diseases remains to be proved.

\section{References}

1. Messigen LM, Callens T, Mortier G, Beysen D, Vandenbroucke I, Van Roy N, et al. Exhaustive mutation analysis of the NF1 gene allows identification of $95 \%$ of mutations and reveals a high frequency of unusual splicing defects. Hum Mutat. 2000;1 5:541-555.

2. DiSimone RE, Berman AT, Schwentker EP. The orthopaedic manifestation of neurofibromatosis: a clinical experience and review of the literature. Clin Orthop. 1988;230:277-283.

3. Kaushik P. Palindromic rheumatism: a descriptive report of seven cases from North Dakota and a short review of literature. Clin Rheumatol. 2010;29:83-86

4. Hannonen P, Möttönen T, Oka M. Palindromic rheumatism. A clinical survey of sixty patients. Scand J Rheumatol. 1987; 16:413-420.

5. Illés $T$, Halmai $V$, de Jonge $T$, Dubousset J. Decreased bone mineral density in neurofibromatosis-1 patients with spinal deformities. Osteoporos Int. 2001;12(10):823827.

6. Petramala L, Giustini S, Zinnamosca L, Marinelli $C$, Colangelo L, Cilenti $G$, et al. Bone mineral metabolism in patients with neurofibromatosis type 1 (von Recklinghausen disease). Arch Dermatol Res. 201 2;304(4):325-331.

7. Bahadir C,Gürleyik G,OcakE. Neurofibromatosis type 1 and primary hyperparathyroidism with spinal deformity and osteoporosis. Acta Chir Belg. 2009;109(1):123-125.

8. Vayssade M, Tatar Z, Soubrier M. Palindromic rheumatism. Rev Med Interne. 2013;34(1):4752.

10. Julkunen $\mathrm{H}$. Palindromic rheumatism or incipient rheumatoid arthritis-chances of drug therapy. Duodecim. 2014;130(19):1923-1928. 